\title{
Hydrothermal Synthesis of Soluble Organic Molecules Starting from the Solar O/C/N Ratio
}

\author{
S. NAGAHISA ${ }^{1}$, S. TACHIBANA ${ }^{1,2}$, S. SHIMAMURA ${ }^{3}$, AND \\ Y. TAKANO 3 \\ ${ }^{1}$ Dept. Earth Planet. Sci./UTOPS, The University of Tokyo \\ ${ }^{2}$ Inst. Space Astron. Sci., JAXA \\ ${ }^{3}$ Japan Agency for Marine-Earth Science and Technology
}

Soluble organic molecules (SOM) in carbonaceous chondrites (CCs) could have formed through hydrothermal reaction in planetesimals. Organic molecules such as $\alpha$-amino acids and sugars are known to be synthesized from simple molecules such as formaldehyde, ammonia, and water under hydrothermal conditions [1-3]. However, when the bulk composition of experimental SOMs was compared with that of Murchison CM chondrite, the $\mathrm{H} / \mathrm{C}$ ratio of synthesized SOMs was inconsistent with the chondritic SOM being enriched in $\mathrm{H}$ [4]. In this study, we conducted hydrothermal synthesis of SOMs with the $\mathrm{O} / \mathrm{C} / \mathrm{N}$ ratio equivalent to the solar abundance as a reference to the ice.

A mixture of paraformaldehyde, glycolaldehyde, ammonium hydroxide and ultra-pure water was sealed with or without minerals (synthetic forsterite and San Carlos olivine) in pyrex tubes [4], and heated in an electric oven at 60,90 and $150^{\circ} \mathrm{C}$ for 3,6 , and 30 days. Water soluble components of run products were filtrated and diluted with $\mathrm{H}_{2} \mathrm{O}$ and methanol to analyze with capillary electrophoresis - mass spectroscopy (Orbitrap Fusion) as a positive ion mode. The SOMs extracted with hot water from Murchison $\left(110^{\circ} \mathrm{C}, 12 \mathrm{hr}\right)$ were also analyzed for the mass spectra together with the software ATTRIBUTOR [5].

The bulk $\mathrm{H} / \mathrm{C}$ ratio of the hydrothermally synthesized SOM was found to be influenced the most by the composition of the starting solution rather than the heating temperature or the presence of minerals. The $\mathrm{H} / \mathrm{C}$ ratio of the SOMs in this study is higher than that of SOMs synthesized in [4], and is close to that of Murchison SOMs. The N/C and O/C ratios of the synthesized SOMs in this study seem also to be consistent with those of Murchison SOMs. Therefore, the bulk chemical characteristics of SOMs in Murchison potentially require the solar $\mathrm{C} / \mathrm{N} / \mathrm{O}$ elemental ratio as the starting composition of hydrothermal reaction if they formed on the parent body.

References: [1] Kebukawa Y. et al. (2017) Sci. Adv. 3, e1602093. [2] Koga T. \& Naraoka H. (2017) Sci. Rep. 7, 636. [3] Furukawa Y. et al. (2019) PNAS, 116, 24440. [4] Isono Y. et al. (2019) Geochem. J. 53, 41. [5] Orthous-Daunay F. -R. et al. (2019) Geochem. J. 53, 21. 